\title{
Supermarket Management Information System
}

\author{
Yixin Lu,Aimin Du,Honglei Bian \\ Information Technology Engineering College, Foshan University of Science and Technology, Guangdong, China
}

\begin{abstract}
This article is mainly about the supermarket inventory management information system environment, function, the language used, the design of the program and other aspects of the content. It is mainly allow users to understand the system, so that they can use the system effectively, and allow the system to play its roles. The system uses computer management information technology, the establishment of the database, the supermarket inventory process to conduct a detailed analysis, to achieve the supermarket purchase, sales and inventory of scientific management. The system mainly includes the following major modules: Key In the invoices: Shipping, Warehousing, List of finished products; Query: Query on shipping and warehousing, Query on finished products list; Sales: Sales Costs Sales Refunds/Returns; Print Report: Warehouse Report, Outbound Report; Finished Product List Report: Sales Refund Report Return/Return Report.
\end{abstract}

Key words: Sales; Database; Management Information System

\section{Chapter 1 Feasibility Analysis}

\subsection{Economic feasibility}

Due to the hardware (computer and related hardware) and software environment (java and Access small database) required by the small supermarket management system, it is easy to buy on the market or download from the related website. The costs of the system mainly concentrates on the development of the management system maintenance, the supermarket does not cause excessive economic burden. And once the system put into use, not only can reduce the intensity of the work of the supermarket, improve work efficiency, but also to facilitate the management of the supermarket information, continuing the traditional management model, bringing great convenience to the supermarket management personnel. Besides, the target system is very complicated, and its development cycle is short, and having small personnel economic expenditure. The savings of a large number of human and financial benefits will be far greater than the development cost of the management system, so the economic development of this system is feasible.

In terms of economic expenditure, the following basic costs are included:

Equipment costs:

Other one-time expenses:

Unforeseen expenses

Recurrent expenditure:

Staff costs

System maintenance fee

Equipment maintenance fee

Consumes material costs

Benefit:

One-time benefit

Recurrent benefits

\subsection{Technical Feasibility}

Supermarket management system is the main background database of two aspects, which are: establishment and maintenance. For the requirements of the establishment, their requirement are very low, did not design in a very detail way. However, fir the maintenance section, they must be very strong and the latter is required to establish data consistency and integrity, having data security and good library.

The system is intended to use Access as a back-end development tools.
Microsoft Access is a relational database, a relational database consisting of a series of tables consisting of a series of rows and columns, each row being a record, each column is a field, each field has a field name, and field name cannot be repeated in a table. The Access database is saved as a file, and the file extension is named MDB.

\section{System Description:}

Firstly login to the interface of the supermarket. However this network only allows the internal staff to enter, and then will go to the overall interface. In order to achieve the system security line, the management of each functional module must be authenticated to enter, for example: the buyer can enter the purchase management module. Salesman can go into the module or section of sales management, etc. The supermarket administrator has the full management authorization, to manage the system. Each person to pay their duties, manages their own roles and modules, and manages the overall operation of this market system.

Therefore, it is feasible to develop this system from a technical point of view.

1.3 Operational Feasibility

Supermarket is a commodity resource distribution point. The main function is to create a space let customer buy the thing openly. For the traditional supermarket management system, there are two general ways: First, manual management, this type of management is the most traditional way of operating system which are using pen and paper to record down everything including the supermarket's cargo information, sales information, vendor information management and document management. The information are in the form of records on the papers, and then unified preservation. Although this method will bring certain convenience while in the simple information but there are more inconvenience. For example: information retention time and conditions are very limited, easy to be damaged, the information query inconvenience, information transmission is likely to cause mistakes and so on.

The general way is a common information management method, which is called the application of stand-alone version. However, this system had designed earlier before, a lot of functional division is not very scientific, and many settings have been unable to keep up with the needs of the times. Fortunately, the supermarket management staff has a considerable application experience, so the new system operation has a certain operating experience.

The size of the supermarket is general and standard, the 
supermarket information processing will strive to be accurate and information, sales information, warehouse information and so on. standardized.

1.4 Analysis on Social Factors Feasibility

The project is independently developed, technically not using any existing software and methods. So there will be no legal infringement of patent rights, infringement of copyright and other issues, in full compliance with the obligations of the contract.

1.5 Analysis on the Users feasibility

The staffs that use the software are required to have a certain computer-based personnel and experience. The system administrator must be the computer's expertise, and all staffs have to go through the company's training.

Managers are also subject to general training. The trainer will be skilled in using the software.

There is also to improve the user feasibility, expand the users on this system, improve operational efficiency and reduce working hours.

In summary, the supermarket is necessary, but also very qualified to do online information and online management to meet the needs of the times and supermarket development needs.

\section{Chapter 2 Software Requirements Analysis}

2.1 System functions:

1. Purchase management

The main function of the purchase management is to add query of the order, to achieve the addition of the number of goods. In this function and the design, already add-on the sub-query function. That is, users inquire (such as purchase number, commodity number, supplier number) according to their needs. Such as follows:

(1) goods to add

(2) purchase orders

(3) purchase orders to add

2. Sales management

Sales management is mainly let sellers to be involved in the situation such as make enquiries, and also to know their sales record.

\section{HR management}

Personnel management is mainly in charged to the management of supermarket personnel and the management of the manufacturers, including the management of supermarket personnel, including the addition of personnel, the removal of supermarket personnel, update staff information and query staff information. The management subfunctions for the vendor are similar to those for supermarket personnel management. as follows:

(1) add workers

(2) delete the workers

(3) update the staff information

(4) query employee information

(1) to add manufacturers

(2) to remove the manufacturer

(3) update the vendor information

(4) query vendor information

4. Inventory management

Mainly involved on the inventory of goods. It is to carry out the integration of information, according to different information on the remaining amount of goods for inquiries, such as the number of goods, the type of goods, the remaining goods and so on.

\subsection{Business process analysis}

Supermarket management system workflow: the system starts and enter the login interface, the system administrator have to enter the correct username and password, login to the system main operation interface, the system administrator can operate the system related information, including basic information, cargo information, Supplier
The business flow chart of this system is shown in Figure 2-1:

The system is the combination of modern computer technology and the background of supermarket management. It is completely designed based on the management of the borrowed management process design completed. At the same time to expand the scope of services, the initial design of a management platform to facilitate the release and management of information. In order to make the system play a greater role in the management, to achieve the computerization of the work process, improve work efficiency and quality of work, it is proposed the following system development goals:

Specific objectives are as follows:

(1) Simple operation, friendly interface: allow us to control the page layout completely, making the information input work easier; many options, including product information, procurement information, supplier information, sales information, etc. only need to click the mouse then it can be completed.

(2) Can view immediately: the information processing (including add, modify, delete) will be immediately displayed in the corresponding page.

(3) functional: not only includes the common system of information management in all aspects: information entry, browsing, delete, modify, query and other aspects, a complete realization of the system of real-time information management requirements. At the same time, it can be able to update the system interface effectively.

(4) To facilitate the transplant: the system should have practicality, reliability and applicability, while taking into account the advanced nature. For different users, only a little change can be developed for their own characteristics of the supermarket management system. The system interface required data are stored in the data file, as long as the file to make some changes, you can in the system interface to achieve timely updates, reducing the complexity of the system to change the source code.

(5) Dynamic management: the dynamic implementation of the system database, to achieve dynamic information on the database query, dynamic updates and dynamic changes to enter the data.

2.3 Data flow analysis

Data flow analysis mainly includes the analysis of information flow, transfer, processing, storage and so on. The purpose of data flow analysis is to find and solve the problem of data flow. The existing data flow analysis is mostly through the hierarchical data flow diagram (data flow diagram, referred to as DFD) to achieve. The specific approach is: according to the business process diagram out of the business process sequence, the corresponding investigation process of the data processing process, drawn into a complete set of data flow chart.

Supermarket management system including 2 data flow: the system operation of the data source of ordinary users and administrators. First is the system administrator having to according to the needs of different users to save some information to the database, and then release. Users can add, modify, and delete this library information. All users can query information. Through the analysis of the needs of the system, the basic functions of the system have been identified.

2.3.1 The flow chart of small supermarket management system

2.3.2 Data needs of supermarket management system

The data requirements of the supermarket management system are including:

1. Data entry and processing accuracy and real-time 
Whether the data input is accurate is the premise of data processing, the wrong input will the system output become incorrect and unavailable. Then, the work of the system will become meaningless. The input source for the data is entered manually. Manual input through the system interface to arrange the system must be allow the error to occur, and the operator must be trained.

In the system, the data input is often mass, so the system must have a certain processing power to ensure rapid processing of data.

2. Data consistency and completeness

To achieve the storage of goods and sales information centralized management, the supermarket product sales management has become systematization, standardization, networking and automation. At the same time, people have to ensure that the consistency of these data must be able to solve the problem. To solve this problem, there must be a certain degree of staff to maintain data consistency, data entry at the control of the whereabouts of data, and requires the database data integrity of the strict constraints.

For the input data, for which to define the integrity rules, if the integrity constraints cannot be met, the system should reject the data.

3. Data sharing and independence

The data of the entire supermarket management system is shared. However, from the perspective of system development, sharing will make design and debugging become difficult. Therefore, it should provide a flexible configuration, so that each sub-system can run independently, and through manual intervention means for the exchange of system data. In this way, it can also provide the system's robustness.

The logical model of the small supermarket management system is shown below:

2.3.3 Small supermarket management system operating requirements

(1) User interface

The system uses java IDE NetBeans design, the user interface is based on the Windows window interface.

(2) Hardware interface

The basic requirements for running the system are as follows:

CPU: Intel P3 and above;

Memory: 256MB and above;

Hard disk: 10GB and above.

(3) Software interface

JDK1.6

Database server: Access small database.

\subsubsection{Other requirements}

1) System function to achieve the situation: the user can be in the system to achieve a variety of user requirements.

2) System security: the important data for the system are password protected, with a certain degree of security.

3) System fault tolerance: the user input error data are prompted, with good fault tolerance.

4) System closure: the user's closure is better, the user is basically in the message information under the message.

\section{Chapter 3 Overall Design}

3.1 Overview of requirements

Improve the efficiency of the operation of the supermarket, save the financial and material resources, to solve the disorder of the supermarket management.

Reduce errors of the source.
Reduce manpower and equipment costs

Improve processing speed

Improve management information services

Improve scientific decision making

Improve staff utilization

3.2 General overview

3.3 System data flow analysis

Figure 3-1 Supermarket Management System Level 0 map

Figure 3-2 Inventory management section

First layer map

Figure 3-3 Sales Management section

First layer map

Figure 3-4 Purchase Management Section

First layer map

Figure 3-5 Personnel Management Section

First layer map

3.5 Data dictionary

Data stream entry

(1) Information on purchased product $=$ purchase number + supplier number + product name + purchase price + purchase quantity + purchase date + note

(2) Sales information $=$ sales number + product number + sales volume + sales date

File entry

(1) File name: Employee list

Composition: $\{$ employee number + name + gender + native + education + category + wages + phone + contact + ID number + date of employment + date of preparation + note $\}$

Organization: Increased by employee number

(2) File's name: list of goods

Composition: \{product number + supply number + name + bar code + unit of measurement + category + origin + price + note $\}$

Organization: Ascending by item number

(3) File name: supplier list

Composition: $\{$ Supplier number + name + contact + contact + contact + bank + bank account + note $\}$

Organization: Increased by vendor number

(3) File name: purchase list

Composition: \{purchase order number + product number + supplier number + purchase price + quantity + amount + purchase date + note $\}$

Organization: Ascending order by order number

(4) File name: Sales list

Composition: \{sales order number + product number + sales volume + sales date $\}$

Organization: Ascending by sales order number

(5) File name: Inventory list

Composition: \{product number + stock quantity\}

Organization: Ascending by item number

Processing instructions

(1) Processing name: 1: query

Processing logic: According to the inventory information to be inquired, the inventory information is retrieved

Input stream: inventory information query, issue an inventory request

Output flow: inventory information list, purchase information 
request

(2) Processing name: 1: update

Update inventory information based on purchase information or sales information

Input stream: incoming information, sales information

Output stream: issue an inventory retrieval request

(3) Processing name: 2: query

According to the sales information to be inquired, the sales information schedule is retrieved

Input flow: sales information query

Output flow: sales list, sales order

(4) Processing name: 2: update

Processing logic: a more detailed sales list based on sales information

Input flow: foreground sales information, inventory information Output stream: Update inventory list

(5) Processing name: 3: query

Processing logic: According to the purchase of information to query, retrieve the purchase information schedule

Input stream: purchase information query, issue purchase / purchase list query

Output stream: inventory information list, incoming purchase information, new supplier information, purchase list information list, purchase order, purchase information request, purchase / purchase list search results

(6) Processing name: 3: update

Processing logic: Update the purchase order based on the purchase information

Input stream: purchase information request, purchase order

Output flow: issue purchase / purchase list query

(7) Processing name: 4: query

Processing logic: according to enter the information to be consulted or supplier information, retrieve the corresponding results

Input stream: employee information inquiry, supplier information inquiry, issue employee / supplier list inquiry

Output stream: existing supplier information, supplier information list, employee information list, employee / supplier list search result

(8) Processing name: 4: update

Processing logic: Update the corresponding list of workers or suppliers based on the input of employee information or new supplier information

Input stream: employee information, new supplier information list, employee / supplier list search result

\section{Chapter 4 detailed design}

4.1 System function chart

The overall structure of the system is shown in Figure 5-1:

Figure 5-1 Supermarket management system function chart

\subsection{System function design}

System function design is to make the whole system can basically realize the supermarket's entry, sales, storage and other management functions, allowing supermarket managers to more intuitive understanding of the operation of the supermarket to make the appropriate business decisions. Management information system (MIS) is to establish the correct database of these resources, and information collection, transmission, storage, compiled into a variety of documents, statements, accounting, graphics and other information, while the maintenance of these information, through the measured Supermarkets and the use of the past historical data to predict the future development of the supermarket from the perspective of the overall decision-making, the use of information control supermarket behavior, pay attention to the supermarket to complete its goal.

The system consists of four modules, namely, personnel management module, sales management module, purchase management module, inventory management module. The function of each module is as follows:

1. Personnel management module function:

(1) To achieve the staff information query;

(2) To achieve the staff information updates, including the addition, deletion, modify the function;

(3) To achieve the supplier information query;

(4) To achieve the supplier information updates, including the addition, deletion, modify the function.

2. Sales management module features:

(1) To achieve sales information query;

(2) To achieve the inventory of merchandise sales.

3. Purchase management module function:

(1) To achieve the purchase of information inquiries;

(2) To achieve the purchase of information updates, including the addition, delete, modify the function.

4. Inventory management module function:

(1) To achieve the query of commodity information;

(2) To achieve the update of commodity information, including the addition, deletion, modify the function;

(3) To achieve the inventory information query;

(4) To achieve the inventory information updates, including the addition, delete, modify the function.

4.3 System database design

1. E-R model

2. Database table design

By the data model using SQL Server 2000 for detailed design of the database, the basic table design is as follows:

(1) Staff List (StaffBill)

$\begin{array}{clclcr}\text { 中文字段名 Field Name } & \text { Type } & \text { of } & \text { Field Name } \\ \text { Length } & \text { Foreign Key / Primary Key } & \text { Data constraint } \\ \text { 职工编号 } & \text { staffID char } & 6 & \mathrm{P} & \text { NOT }\end{array}$

NULL

姓名 name nvarchar 8 NOT

NULL

$\begin{array}{lllll}\text { 性别 } & \text { sex } & \text { nchar } 2 & \text { NOT } \\ \text { NULL } & & & & \end{array}$

籍贯 home nvarchar 4 NULL

学历 diploma nvarchar 4 NOT

NULL

类别 kind nvarchar 10 NULL

工资 salary int 4 NULL

联系电话 phone varchar 12 NULL

联系地址 address nvarchar 50 NULL

身份证号 idCard varchar 18 NOT

NULL

$\begin{array}{lll}\text { 聘用日期 } & \text { beginDate } & \text { datetime } 8 \\ \text { NULL } & & \\ \text { 编制日期 } & \text { enactTime } & \text { datetime } 8 \\ \text { NULL } & & \\ \text { 备注 } & \text { others ntext } & 50\end{array}$

NULL 
employee.

$$
\begin{array}{clcll}
\text { 中文字段名 } & \text { Field Name } & \text { Type } & \text { of Field Name } \\
\text { Length } & \text { Foreign Key / Primary Key } & \text { Data constraint } \\
\text { 帐号 } & \text { loginID char } & 6 & \text { P/F } & \text { NOT }
\end{array}
$$

NULL

$\begin{array}{lll}\text { 密码 } & \text { NOSsWordchar }\end{array}$

NULL

Password pass Word char 6 NOT NULL

(3) Merchandise List (MerchBill)

中文字段名 Field Name Type of Field Name

Length Foreign Key / Primary Key Data constraint

$\begin{array}{lllll}\text { 商品编号 merchID char } & 6 & \mathrm{P} & \text { NOT }\end{array}$

NULL

供货商号 profferID char 6 F $\quad$ NOT

NULL

名称 fullName nvarchar 80 NOT

NULL

NULL

条形码 barCode char $15 \quad$ NOT

计量单位 metricUnit varchar 4

NOT NULL

类别 kind nvarchar 8

产地 birthPlace nvarchar 50

NULL

NULL

NULL

单价 unitCost money 4

NOT

备注 others ntext $50 \quad$ NULL

(4) Supplier list (ProfferBill)

Note: This table stores vendor information.

中文字段名 Field Name Type of Field Name

Length Foreign Key / Primary Key Data constraint

供货商号 profferID char $6 \quad 6 \quad \mathrm{P} \quad$ NOT

NULL

名称 fullName nvarchar 50 NOT

NULL

联系人 contactPerson nvarchar 8

NOT NULL

联系电话 phone varchar 12 NOT

NULL

联系地址 address nvarchar 50 NOT

NULL

开户行 openingBank nvarchar 10

NULL

银行帐号 accountID varchar 15

NULL

备注 others ntext 50

NULL

(5) Purchase list (ImportBill)

中文字段名 Field Name Type of Field Name

Length Foreign Key / Primary Key Data constraint

进货单号 importBillID char $6 \quad$ P

NOT NULL

$\begin{array}{lllll}\text { 商品编号 merchID char } 6 & \text { P/F } & \text { NOT }\end{array}$

NULL

NULL

供货商号 profferID char 6 F $\quad$ NOT

进货价 importPrice money 4

NOT NULL

数量 quantity int 4 NOT

NULL

金额 totalMoney money

NOT NULL

进货日期 importDate datetime 8

NOT NULL

备注 others ntext 50

NULL

Description: This table stores the purchase information.
(6) Sales List (SaleBill)

中文字段名 Field Name Type of Field Name

Length Foreign Key/Primary Key Data constraint

销售单号 saleBillID char $6 \quad$ P

NOT NULL

商品编号 merchID char $6 \quad$ P/F $\quad$ NOT

NULL

NULL

销售数量 saleNum int 4 NOT

销售日期 saleDate datetime $8 \quad$ NOT

NULL

Description: This table holds sales information.

(7) Inventory list (StoreBill)

中文字段名 Field Name Type of Field Name

Length Foreign Key / Primary Key Data constraint

商品编号 merchID char $6 \quad \mathrm{P} / \mathrm{F} \quad \mathrm{NOT}$

NULL

库存数量 storeNumint 4

NOT

NOT

\section{NULL}

Chapter 5 System Testing

The most important thing to do with the coding process is to test the system, the test has two periods in the system design phase, usually after the preparation of each module we to do unit testing, another period is a comprehensive test of the system.

5.1 Module test

In the module test, we mainly start from the following aspects:

1. Module interface

2. Local data structure

3. Important execution channel

4. Error handling channel

5. Impact of the above-mentioned boundary conditions

Test the code review, from the data type, variable declaration, data structure to review, and then functional tests, from the input of some simple data and to start again. Besides, observe the changes during the operation of the variable, the value of the range of operation. Change the test plan to transform the other angle to test, find the error and record, modify the code, test conditions so that the program through the multi-layer branch, determine the results of the operation 
to complete the module test.

5.2 Overall testing

The overall test is the system technology of assembling the software. The system adopts the incremental integration test, that is, the test of a single module, the test module is added to the system, a system test, and so on all the modules into the system, in the specific test. From top to bottom of the combination, starting from the main control module, along the control layer down, gradually put all the modules together.

Use the debugging technique during the test

1. Use the debug statement to track the data

2. Embed the print statement and output the intermediate result

3. Use VF6.0 in the debugging tool, from the immediate window to observe the changes in the variable

4. Set the breakpoint and observe the status of the program near the breakpoint

Evaluate the reliability of the operation

1. The results are correct

2. Running speed

3. Space utilization

4. The feasibility of the algorithm

\section{REFERENCES}

[1] Sha Shixuan, Wang Shan. Introduction to the database system. Beijing: University Education Press, 1985.60-65

[2] Wang Yongling. Computer data processing system analysis and design. Beijing: Tsinghua University Press, 1986.125-130

[3] Zhang Jiwen. Information system development case. Beijing; Tsinghua University Press, 1999.50-60

[4] Management Information System, Lanzhou University Press, 2001.70-80

[5] Bi Shuwei. Management Information System Analysis and Design. Beijing: Mechanical Industry Press, 1992.90-100

[6] Enterprise Management Model and Microcomputer Application Program, Shijiazhuang: Hebei People's Publishing House, 1985.101-120

[7] Introduction to Management Information System, Beijing: Mechanical Industry Press, 1986.189-206 